\title{
Effect of the Calcareous Deposits on the Stress Corrosion Cracking Behavior of 10Ni5CrMoV High Strength Steel in Deep-Sea Environment
}

\author{
Hongbo $X u^{1,2}$, Lin $\mathrm{Li}^{2, *}$, Lina Peng ${ }^{1}$, Hongyu $\mathrm{San}^{2}$, Mingshuang $W u^{1}$, Xiandong $\mathrm{Su}^{2}$ \\ ${ }^{1}$ College of Chemical Engineering, University of Science and Technology Liaoning, Anshan 114051, \\ China. \\ ${ }^{2}$ State Key Laboratory of Metal Material for Marine Equipment and Application, Anshan Iron and Steel \\ Group Corporation, Anshan 114009, China. \\ *E-mail: ansteellilin@163.com
}

doi: $10.20964 / 2021.05 .63$

Received: 3 February 2021 / Accepted: 20 March 2021 / Published: 31 March 2021

The calcareous deposits' effect on the stress corrosion cracking (SCC) behavior of $10 \mathrm{Ni5CrMoV}$ high strength steel in a marine environment was investigated by slow strain rate tests (SSRT) and microscopic observations. The results showed that the hydrogen cracking mainly controlled the SCC mechanism of $10 \mathrm{Ni} 5 \mathrm{CrMoV}$ high strength steel. The SCC sensitivity of both the $10 \mathrm{Ni} 5 \mathrm{CrMoV}$ steel and steel covered with calcareous deposits increased first and then decreased with ocean depth. These were consistent with the hydrogen evolution reaction current density changes, which indicates that the marine environment influenced the susceptibility of SCC by changing the permeated hydrogen concentration. Moreover, the sensitivity of SCC decreased obviously when the steel was covered with calcareous deposits. This behavior was mainly attributed to the permeated hydrogen concentration, which was hindered by the calcareous deposits.

Keywords: Calcareous deposits; Deep-sea environment; Stress corrosion; Hydrogen cracking;

\section{FULL TEXT}

(C) 2021 The Authors. Published by ESG (www.electrochemsci.org). This article is an open access article distributed under the terms and conditions of the Creative Commons Attribution license (http://creativecommons.org/licenses/by/4.0/). 